\title{
Presence of Incomplete Superficial Axillary Arch and Pectoralis Quartus Muscle in One Male Body
}

\author{
Presencia en un Individuo de un Arco Axilar Superficial \\ Incompleto y de un Músculo Pectoral Cuarto
}

Alba R. Valencia V. ${ }^{1}$; José I. Salgado ${ }^{1}$ \& José S. Cortés ${ }^{2}$

\begin{abstract}
VALENCIA, V. A. R.; SALGADO, J. I. \& CORTÉS, J. S. Presence of incomplete superficial axillary arch and pectoralis quartus muscle in one male body. Int J. Morphol., 39(5):1353-1357, 2021.

SUMMARY: The anatomical variations of the pectoralis major muscle (PMM) and latissimus dorsi muscle (LDM) range from agenesis to the presence of supernumerary fascicles with a variety of insertions and relationships with the muscles, fascia, vessels, nerves and skeletal components of the shoulder girdle and the axilla. Many of these variations are clinically irrelevant, but extremely interesting and revealing from the perspective of comparative anatomy, ontogeny, and phylogeny. In this report, we present two different supernumerary muscles in the chest of one adult male body, identified during dissection practice of undergraduate medical students at Universidad Surcolombiana. These supernumerary fascicles in the axillary region were caudal to the lower edge of the PMM on the right side of the chest, and in contact with the anterior edge of the LDM on the left side of the chest; each fascicle was inserted in the ipsilateral coracoid process. These observations are congruent with the pectoralis quartus muscle and an incomplete and superficial axillary arch, respectively.
\end{abstract}

KEY WORDS: Anatomy; Anatomic variation; Axilla; Superficial back muscles; Pectoralis muscles.

\section{INTRODUCTION}

Knowledge of muscular, vascular and neural anatomical variations in the axillary region is of clinical importance to the oncologist when performing axillary node biopsy, or to the surgeon when performing a mastectomy, breast reconstruction, axillary bypass or to the plastic surgeon during breast surgery (Taterra et al., 2019). Different bands of muscle, tendon or muscle-tendon tissue that originate from the latissimus dorsi muscle (LDM) or the pectoralis major muscle (PMM) that cross the walls of the axilla have been described. These may cause problems over the neurovascular elements found there.

The PMM has four origin sites, namely: clavicular part, sternal part, costochondral part, and abdominal part. The tendon for its lateral insertion is attached to the lateral lip of the intertubercular sulcus of the humerus; this insertion can be modified by the existence of supernumerary fascicles, which can be fixed either in the coracoid process or the coracobrachialis tendon, in the costal muscle or chondrocoracoid Wood's muscle, in the fascia of the arm, in the greater or lesser tuberosity of the humerus, in the short head tendon of the biceps brachii muscle (BBM); in the medial epicondyle of the humerus, in the chondroepitrochlear muscle (Naldaiz-Gastesi et al., 2018). There may also be supernumerary pectoral muscles called intermediate, tertius, or quartus muscles (Arican et al., 2006; del Sol \& Vásquez, 2009).

The LDM belongs, by its route, to the dorsal, thoracic and axillary regions; it originates in the spinous processes of the six or seven last thoracic vertebrae, of the five lumbar vertebrae and the corresponding interspinous ligaments; in the median sacral crest; the posterior third of the external lip of the iliac crest; on the posterolateral side of the last four ribs and can be inserted in the lower angle of the scapula; its insertion tendon ends at the bottom of the intertubercular sulcus and there it can emit an expansion that binds it to the lesser tubercle of the humerus (Latarjet \& Ruiz Liard, 1995).

Anatomical variations of the muscular structures that cross the region of the axilla are rare, but when they exist, they can cause many problems since the anatomical

\footnotetext{
${ }^{1}$ Department Basic Sciences, Faculty of Health University Surcolombiana. Neiva, Huila, Colombia.

${ }^{2}$ Postgraduate of Internal Medicine, Faculty of Health University Surcolombiana. Neiva, Huila, Colombia.
} 
organization described for the approach of the vascular and nervous elements located there is altered. These bands of muscular or connective tissue are nothing more than vestiges of the panniculus carnosus of the lower mammals, which persists as an embryonic remnant represented in man by the platysma and dartos muscles (Sharma et al., 2009). The bestknown structural variants of the axillary components in man are the fascicles that extend from the LDM to some of the structures on the upper part of the humerus. This type of variation has received multiple names: Langer's axillary muscle, axillary arch, among others. This fascicle crosses in front of the axillary neurovascular bundle and can receive innervation from the lateral pectoral, medial pectoral, thoracodorsal (Khan et al., 2008; Bakirci et al., 2010) or the intercostobrachial nerves (Vishnumikkala, et al., 2013).

The axillary arch is defined as a muscular fascicle measuring 7 to $10 \mathrm{~cm}$ long and 5 to $15 \mathrm{~mm}$ wide, occasionally emerging from the edge of the LDM, approximately halfway along the posterior axillary fold and crossing it in front of the axillary vessels and nerves to join laterally to the inferior surface of the PMM tendon, coracobrachialis muscle fascia, fascia over the BBM, coracoid process of the scapula, pectoralis minor muscle (PmM) or axillary fascia (Jelev et al., 2007). Testut divided the axillary arches into two groups: complete and incomplete arches; the complete axillary arch extends from the LDM to join the PMM; the incomplete can be inserted over the axillary fascia, BBM, coracobrachialis muscle, the lower edge of the PmM, lower part of the intertubercular sulcus or in the coracoid tuberosity.These axillary arches have also been divided into deep, if they are part of the lateral or posterior wall of the axilla, and superficial, if they pass in front of the axillary neurovascular bundle (Bakirci et al.).

The pectoralis quartus muscle $(\mathrm{PQM})$ is described as a variation parallel to the lateral edge of the PMM, whose frequency reported in the literature varies between 11-16\% (Bonastre et al., 2002). It originates from the costochondral junction of the fifth and sixth ribs, the lateral edge of the $\mathrm{PMM}$ or rectus fascia, and is inserted into the bicipital sulcus or the fascia covering the coracobrachialis muscle (Uzmansel et al., 2011) or coracoid process, together with the short head of the BBM or the origin of the coracobrachialis muscle (Hunt, 2017), or the coracoid process (Schafer \& Symington, 1876).

\section{MATERIAL AND METHOD}

In this report, the finding of a parallel PQM separated from the PMM located on the right side of the body and an incomplete and superficial axillary arch originating from the LDM on the left side are described. Both variations were found in the same 72-year-old adult male body whose routine dissection was performed by the first-year medical students of the Faculty of Health at the Universidad Surcolombiana in the city of Neiva Huila, Colombia.

\section{RESULTS}

During dissection of the right PMM, a thin muscle next to the fleshy portion of the abdominal fasciculus of this muscle was found to originate from fleshy fibers on the external face of the seventh and eighth ribs at the level of the costochondral joint, and was inserted into the coracoid process, matching with the definition given in the literature for the PQM (Fig. 1). This PQM was separated from the PMM; only in its middle portion some adhesions were found towards the pectoralis fascia. It was observed that the muscle had two anastomotic portions towards the pectoralis minor muscle that delimited two hiatuses: an upper one, through which the cephalic vein crossed, and a lower one, whose function is unknown; after lifting the muscle band it was observed that it had an independent insertion to that of the PMM, which ended in a small tendon that was inserted in the coracoid process passing over the neurovascular bundle and contributing to the formation of the anterior wall of the axilla (Fig. 2).

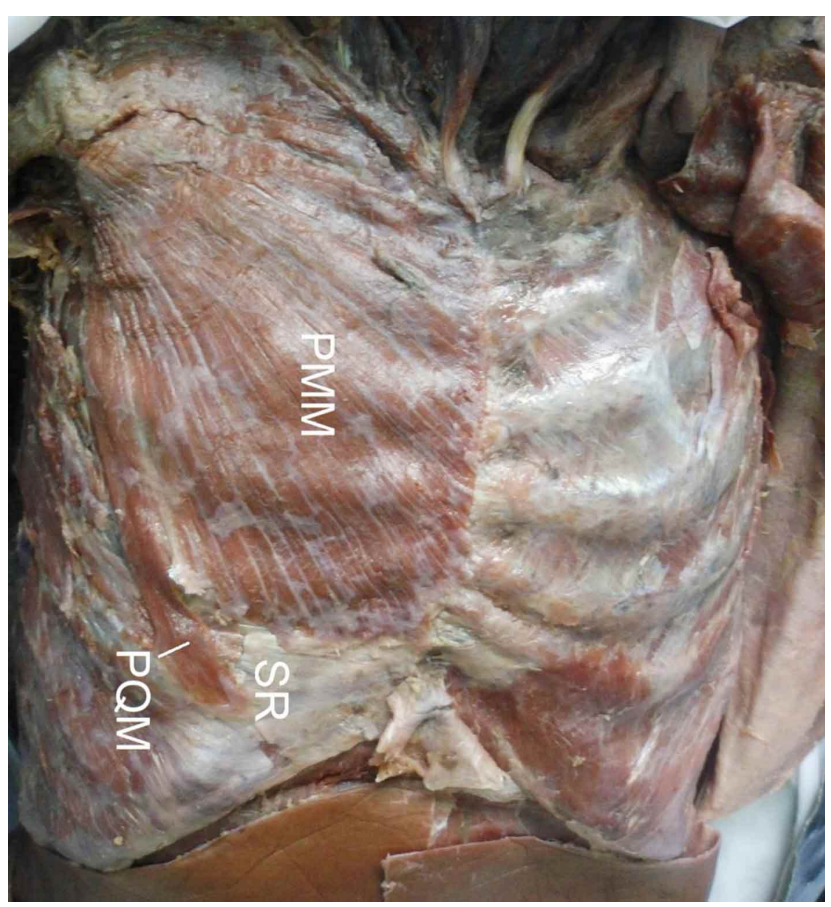

Fig. 1. Upper view of the right chest wall. PMM, pectoralis major muscle; PQM, pectoralis quartus muscle; SR, seventh rib. 


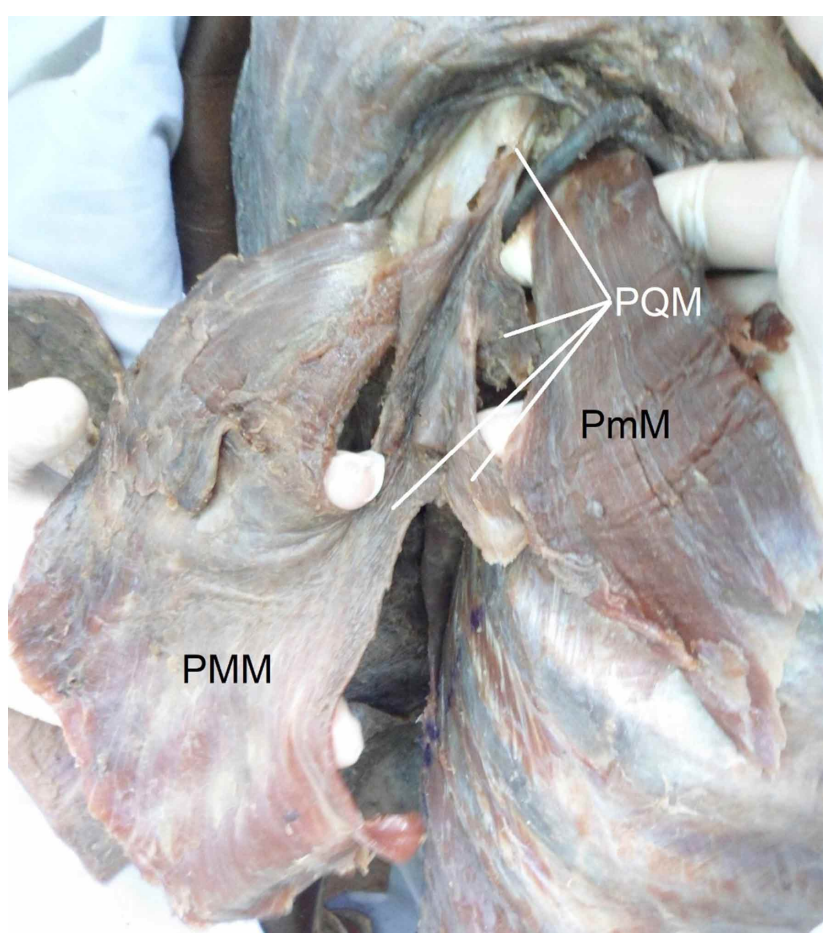

Fig. 2. Upper view of the right chest wall. PMM, pectoralis major muscle; PmM, pectoralis minor muscle; $\mathrm{PQM}$, pectoralis quartus muscle.

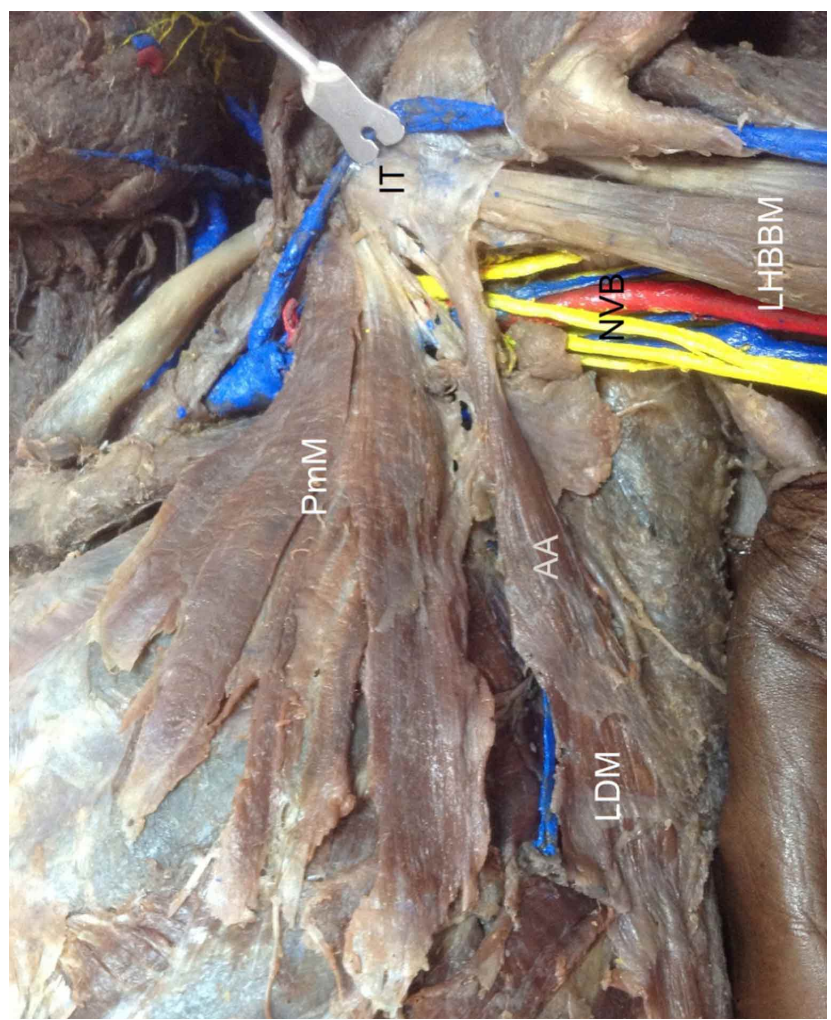

Fig. 3. Upper view of the left axilla. AA, axillary arch; IT, insertion tendon; LDM, lattisimus dorsi muscle; LHBBM, long head of the biceps brachialis muscle; PmM, pectoralis minor muscle; NVB: axillary neurovascular bundle.
When dissection of the axilla and thoracic region on the left side of the body was performed, a supernumerary fascicle that originated from the upper third of the anterior margin of the LDM muscle and was directed towards the left coracoid process passing superficially to the axillary neurovascular bundle was found. We described this fascicle as an incomplete superficial axillary arch (Fig. 3). It was found that the insertion of the axillary arch extended in a fan shape ending over the shoulder joint capsule, the arm fascia and the coracoid process (Fig. 4); we observed that the irrigation came from branches originating from the thoracoacromial arterial trunk, from muscular branches reaching the PmM, and a perforating branch of the intercostal artery of the third space.

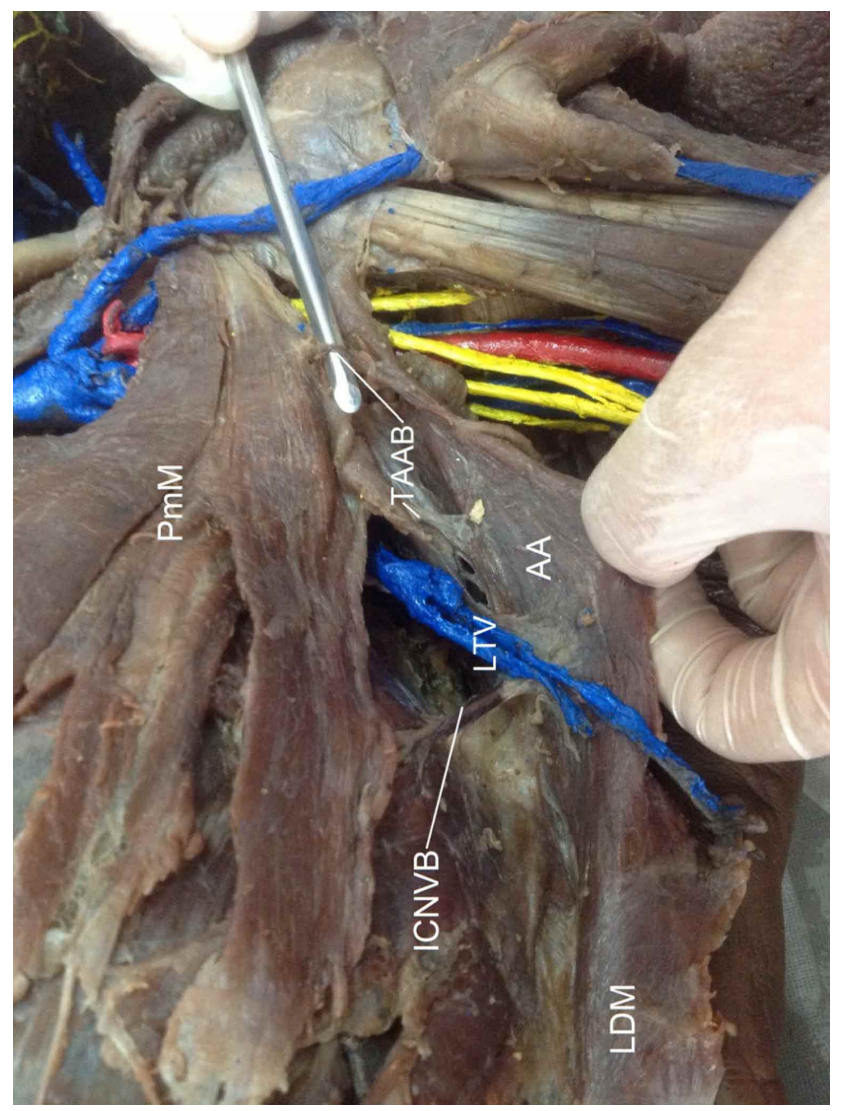

Fig. 4. Upper view of the left axilla. AA, axillary arch; PmM, pectoralis minor muscle; LDM, lattisimus dorsi muscle; ICNVB, intercostal neurovascular bundle; TAAB, thoraco acromial artery branches; LTV, lateral thoracic vein.

\section{DISCUSSION}

There are many muscle variations in the upper limb that are related to PMM and LDM and only become important when they are discovered during surgery or when 
producing the symptomatology of neurovascular compression syndrome due to their relationship with the vascular and nerve bundle of the axilla. Studies in cadavers indicate a low prevalence of these variations, around $4 \%$. (Miguel et al., 2001). However, surgical reports indicate a much higher incidence of $27 \%$ (Mérida-Velasco et al., 2003).

Some authors have pointed out that the muscle bands described here as anatomical muscle variations are nothing more than embryonic remnants of the panniculus carnosus muscle (Inzunza et al., 2008), which gives rise in humans to a striated muscle group that includes the occipitofrontal muscle, auricular muscles, platysma, short palmar of the hand, and the complete or incomplete axillary arch (Naldaiz-Gastesi et al.).

The PQM is considered a very rare anatomical variation in humans and has been reported with a prevalence of $11-16 \%$, compared to the axillary arch which is one of the most common findings of the upper limb with a frequency of 7-27\%; but it uncommon to find both variations in the same individual, which in the literature has been reported with a frequency around $9 \%$ or less. There is a report of a body in which there was simultaneously a PQM on each side, and axillary arch and an epitrochlear muscle (Bonastre et al.; Uzmansel et al.). The presence of a PQM and an axillary arch inserted into the coracoid process and other sites have also been reported in the same individual and on the same side (Bonastre et al.).

Although there are many reports of PQM (Sawada et al., 1991; Arican et al.; Hunt) and axillary arches (Jelev et al.; Khan et al.; Sharma et al.; Mohandas Rao et al., 2011; Uzmansel et al.). These are descriptions of each anatomical variation independently or combined with another type of structure, but there is very little information about this coexistence reported by us. Bonastre et al. reported that other authors have reported the coexistence of the axillary arch and the PQM in the same individual, but the great variability in the way the axillary arch is inserted has produced many muscle combinations.

We have seen that, despite the great discrepancy of concepts regarding the anatomical muscle variations that cross the axillary region and the great number of accessory muscle bands that are related to the LDM and PMM muscles, the two anatomical variations found in this cadaver: PQM and incomplete and superficial axillary arch, coincide with the description found in the literature and made regarding the PQM (Macalister, 1875), and that of an incomplete axillary arch (Macalister; Dharap, 1994; Loukas et al., 2009).
The value of the knowledge of these anatomical variations that involve the axillary region, acquire their importance due to the high frequency of surgical interventions in this area during oncological mammary surgeries, since their lack of knowledge could lead to erroneous interpretations of mammographic images, malpractice during ganglion emptying because they do not allow direct and correct observation of the axilla or the elimination of its contents (Natsis et al., 2010) and when using flaps for breast reconstructions (Longo Meneses \& Aguirre Serrano, 2013).

VALENCIA, V. A. R.; SALGADO, J. I. \& CORTÉS, J. S. Presencia en un individuo de un arco axilar superficial incompleto y de un músculo pectoral cuarto. Int. J. Morphol., 39(5):1353-1357, 2021.

RESUMEN: Las variaciones anatómicas del músculo pectoral mayor (MPM) y del músculo latísimo del dorso (MLD) van desde la agenesia hasta la presencia de fascículos supernumerarios con una variedad de inserciones y relaciones con los músculos, fascias, vasos, nervios y componentes esqueléticos de la cintura escapular y la axila. Clínicamente, muchas de las variaciones son irrelevantes, pero extremadamente interesantes y reveladoras desde la perspectiva de la anatomía comparada, la ontogenia y la filogenia. En este estudio, presentamos dos músculos supernumerarios diferentes en la pared torácica de un hombre adulto, identificados durante la práctica de disección de estudiantes de medicina de la Universidad Surcolombiana. Estos fascículos supernumerarios en la región axilar estaban caudales al margen inferior del MPM en el lado derecho del tórax y en contacto con el margen anterior del MLD en el lado izquierdo del tórax; cada fascículo se insertaba en el proceso coracoides ipsilateral. Estas observaciones son congruentes con el músculo pectoral cuarto y un arco axilar incompleto y superficial, respectivamente.

PALABRAS CLAVE: Anatomía: Variación anatómica; Axila; Músculos superficiales del dorso; Músculos pectorales.

\section{REFERENCES}

Arican, R. Y.; Coskun, N.; Sarikcioglu, L.; Sindel, M. \& Oguz, N. Coexistence of the pectoralis quartus and pectoralis intermedius muscles. Morphologie, 90(290):157-9, 2006.

Bakirci, S,; Kafa, I. M.; Uysal, M. \& Sendemir, E. Langer's axillary arch (axillopectoral muscle): a variation of latissimus dorsi muscleos ilium. The axillary arch is a variant muscular slip of this muscle. Int. J. Anat. Var., 3:391-2, 2010.

Bonastre, V.; Rodríguez-Niedenführ, M.; Choi, D. \& Sañudo, J. R. Coexistence of a pectoralis quartus muscle and an unusual axillary arch: case report and review. Clin. Anat., 15(5):366-70, 2002.

del Sol, M. \& Vásquez, B. Anatomical and clinical considerations of the pectoralis tertius muscle in man. Int. J. Morphol., 27(3):715-8, 2009. 
Dharap, A. An unusually medial axillary arch muscle. J. Anat., 184(Pt. 3):639-41, 1994.

Hunt, J. D. Bilateral pectoralis major and pectoralis quartus variants?: A conjoined tendon passing through the inter tubercular groove. Int. J. Anat. Var, 10:88-90, 2017.

Inzunza, O.; Marín, A.; Pino, F.; Navarrete, C. \& Vargas, A. Panniculus carnosus, vestigial remanents in the axillary region. Int. J. Morphol., 26(4):841-4, 2008.

Jelev, L.; Georgiev, G. P. \& Surchev, L. Axillary arch in human: common morphology and variety. Definition of "clinical" axillary arch and its classification. Ann. Anat., 189(5):473-81, 2007.

Khan, M. M.; Darwish, H. H. \& Zaher, W. A. Axillary arch: A rare variation. Eur. J. Anat., 12(3):169-73, 2008

Latarjet, M. \& Ruiz Liard, A. Anatomía Humana. Vol. I. Bogotá, Médica Panamericana, 1995

Longo Meneses, J. \& Aguirre Serrano, H. Presentación bilateral del músculo axilopectoral. Reporte de caso. Morfolia, 5(1):20-8, 2013.

Loukas, M.; Noordeh, N.; Tubbs, R. S. \& Jordan, R. Variation of the axillary arch muscle with multiple insertions. Singapore Med. J., 50(2):e8890, 2009.

Macalister, A. Additional observations on muscular anomalies in human anatomy (Third Series) with a catalogue of the principal muscular variations hitherto published. Trans. Roy. Irish Acad., 25:1-134, 1875.

Mérida-Velasco, J. R.; Rodríguez Vázquez, J. F.; Mérida Velasco, J. A.; Sobrado Pérez, J. \& Jiménez Collado, J. Axillary arch: potential cause of neurovascular compression syndrome. Clin. Anat., 16(6):514-9, 2003.

Miguel, M.; Llusá, M.; Ortiz, J. C.; Porta, N.; Lorente, M. \& Götzens, V. The axillopectoral muscle (of Langer): report of three cases. Surg. Radiol. Anat., 23(5):341-3, 2001.

Mohandas Rao, K.; Somayaji, S.; Narendra, P. \& Surekha, D. S. An unusual case of axillary arch bridging across the anterior and posterior axillary folds in the distal part of axilla. Int. J. Anat. Var., 4:128-30, 2011.

Naldaiz-Gastesi, N.; Bahri, O. A.; López de Munain, A.; McCullagh, K. J. A. \& Izeta, A. The panniculus carnosus muscle: an evolutionary enig$\mathrm{ma}$ at the intersection of distinct research fields. J. Anat., 233(3):27588, 2018

Natsis, K.; Vlasis, K.; Totlis, T.; Paraskevas, G.; Noussios, G.; Skandalakis, P. \& Koebke, J. Abnormal muscles that may affect axillary lymphadenectomy: surgical anatomy. Breast Cancer Res. Treat., 120(1):77-82, 2010

Sawada, M.; Ishibashi, Y.; Suzuki, T. \& Chiba, S. Case reports on the pectoralis quartus and the pectoralis intermedius muscles. Kaibogaku Zasshi, 66(2):99-105, 1991.

Schafer, E. S. \& Symington, J. B. T. Quain's elements of anatomy. J. Anat., 10(Pt. 2):99-104, 1876

Sharma, T.; Singla, R. K.; Agnihotri, G. \& Gupta, R. Axillary arch muscle. Kathmandu Univ. Med. J., 7(28):432-4, 2009.

Taterra, D.; Henry, B. M.; Zarzecki, M. P.; Sanna, B.; Pe ‘kala, P. A.; Cirocchi, R.; Walocha, J. A.; Tubbs, R. S. \& Tomaszewski, K. A. Prevalence and anatomy of the axillary arch and its implications in surgical practice: A meta-analysis. Surgeon, 17(1):43-51, 2019.

Uzmansel, D.; Kara, A. \& Kurtog $`$ lu, Z. Unusual axillary arch and accompanying musculofascial variations: case report. Turkiye Klin. J. Med. Sci., 31(4):1011-4, 2011.

Vishnumikkala, T.; Yalakurthi, S. \& Bharath, N. C. An axillary arch muscle and its clinical importance - A case report. Int. J. Med. Health Sci., 2(2): 251-255, 2013.

\author{
Corresponding author: \\ Alba Rocio Valencia Valderrama \\ Facultad de Salud \\ Universidad Surcolombiana \\ Calle 9 No 14-02 \\ Neiva 410010 \\ Huila \\ COLOMBIA
}

E-mail: albarocio.valencia@usco.edu.co

Received: 18-05-2021

Accepted: 28-06-2021 